\title{
Research on the Construction of Cross-professional Teaching Mode of Visual Communication Design
}

\author{
Shen Lei \\ School of Art and Design, Wuhan University of Technology, Wuhan, China, 430007
}

Keywords: visual communication; interdisciplinary; subject

Abstract: The visual communication design profession is a practical specialty. However, the teaching effect of the art education curriculum in China is not significant. It does not form a scientific system of practical teaching system, and the value of the existing curriculum. It is not fully reflected. Under this development situation, how to deal with the "quality" of teaching in the teaching relationship of art design courses and the "quantity" of students in the course of visual communication design, how to establish the unity of teaching ideas and guidelines for higher art design, how to Reform the goal of art design teaching, the mode and method of teaching. And the research on the sustainable development of design disciplines, all of which require us to have a deeper understanding and understanding of contemporary art design teaching, and make scientific! The correct judgment of the combination of theory and countermeasures and concrete implementation.

\section{Introduction}

China's modern design education class has taught students from the original theory and technology, and gradually turned into a developmental and inspiring education model to cultivate and stimulate students' creative thinking.

\section{Improve the teaching system setting and teaching mode}

First of all, from the professional characteristics of the course, the visual communication design profession can break through the traditional "cramming" teaching method through the heuristic teaching mode, focusing on the combination of practice and teaching, and linking the teaching with the society and the market. Stimulate students' desire and interest in new knowledge, and guide students to interest in the curriculum through a large number of examples. A large number of practical and objective examples of analysis and demonstration, leaving students with sufficient space for thinking and proposing purposeful research topics[1].

\subsection{Teaching mode of visual communication design professional practice teaching}

Visual Communication Design Specialty We can use group teaching methods through practical teaching. Generally, in the art teaching, in addition to theoretical classes, professional courses are basically practical. It is mainly to cultivate students' hands-on practical ability and exercise design 
and creative ability. This is to start from the training goal of art visual communication and let students face the market. Under the guidance of the teacher, actively participate in the training of various project design topics and improve the design team of the students. Learn to find information, analysis cases, market research and sales market research. Discover the ability of the problem to solve the problem, complement the deficiencies in the classroom, and the resilience in the design. Better adapt to society.

\subsection{Visual Communication Design Professional Collaborative Participation Teaching Mode}

"Collaboration" is the means of "participation" and "participation" is the way of "collaboration". Why do we focus on the teaching mode of collaborative participation? In the process of teaching, it is not only in the process of classroom teaching, but also provides students with the overall ability to collaborate in future work, laying the foundation for communication, communication and coordination. . Teachers choose topics, students are divided into small groups to discuss and establish a collective spirit of collaboration with others. Through the strengthening of coordination ability, we can get rid of the limitations of students' individual thinking and let the design thinking be perfectly presented under the collective attention of the team. Make the whole teaching in the "collaborative teaching mode reflects the innovation of the teacher teaching model."The level of visual communication teaching is shown below.

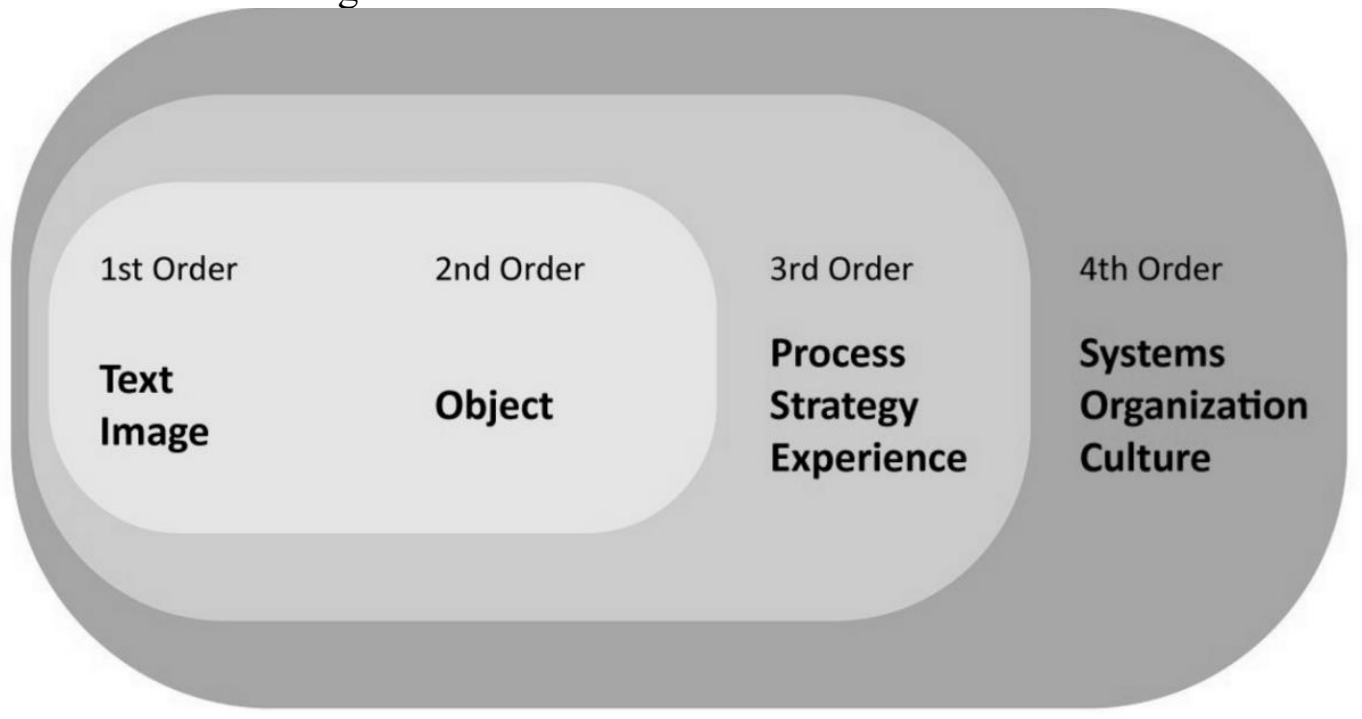

Fig.1 Level of visual communication teaching

\section{3 visual communication design professional personality dominant teaching mode}

Personality-oriented teaching is to strengthen and promote the development of students, highlight the characteristics of art students, and demonstrate the advantages of their individual design advantages. We propose a personality advantage teaching. Students show their stable personality advantages in the process of personality development, which indicates his future development direction and lays a solid practical foundation for future development. Our teachers should try to understand as much as possible the parts of the students that distinguish their distinctive personality, find their shining points, and guide students to improve the design plan, adopt the teaching methods of encouragement, inspiration and affirmation, and provide students with their individuality. The stage of talent. From the past teaching methods, academic achievement is transformed into practice as the only criterion for evaluating students, and the individuality is highlighted. In the process of students commenting on their respective design plans, teachers should 
give full play to the students' potential, thus stimulating students' self-affirmation, self-expression and self-development awareness[2].

\section{4 visual communication design professional creative teaching mode}

Art students have their own unique imaginations and ways of thinking. Creative teaching is mainly a teaching method with the main goal of cultivating students' creative ability. Students are no longer limited and bound by existing knowledge and traditional concepts in a free teaching atmosphere. The creative teaching method is mainly to break the traditional teaching method, encourage students to break through the knowledge in books, use practice to give their different ways and methods through creative analysis, and cultivate the purpose of creative talents. From the teaching focus on stimulating and cultivating students' independent thinking, creative thinking and the ability to discover new knowledge[3].

\section{Visual communication professional teaching mode focuses on the purpose of practical research}

The purpose of attaching importance to practical research is to better play the important functions of visual communication art students in serving the economy and cultivating innovative talents. It is also to update the educational concept, to make students closer to the market, to better face the future; to explore a unique training mode, thus changing the previous training mode based on skill training, adopting multi-disciplinary infiltration and focusing on practical hands-on ability. The training mode of modern graphic designers; the innovation and expansion of the teaching methods we have tried for this purpose is to not only master the basic skills of image thinking, but also have the logical thinking ability of comprehensive analysis, so as to achieve the purpose of teaching by analogy. Make teaching subtle and provide the best expression for design creativity and production.

Good design works need to know each other. The so-called confidant is to understand the visual function of human beings from the visual subject and to study the real state of the perceptual process; the so-called knowledge is to understand the relative relationship of forms from the perspective of visual objects. For design, it is not only to solve the problem of communication mode and speed of communication, but more importantly, to disseminate effective information. Disseminating effective, accurate and reliable information is the primary principle for designing information dissemination. It is an important guarantee for design success. The target of communication is the audience formed by people and people. Whether the design element can resonate with the viewer's visual experience depends on the interaction of the power of the stimuli's structure with the forces it evokes about the memory traces. In visual communication, design is a dialogue with the audience in a single or continuous form. How to choose the focus of the dialogue is the key to success. The audience accepts certain information through contact with the design works (visual, listening, dynamic, etc.), and then he will test this with his own life experience and aesthetic experience, with the standards of the public and with the life itself as a reference. Information, so that it is judged whether it is accurate or not, whether it is reliable or not, whether to accept the design information, and to influence the attitude of people around it to the design information. Thus, it is a good choice to put the visual representation of visual communication design into a specific cultural context to infect the spiritual world of the audience[4].

We can compare the Eastern and Western cultures. Due to the different geographical environment and humanistic environment, East and West squares have become different cultural values and different psychological structures and aesthetic psychology. This difference has outstanding performance in visual communication design. For example, the Chinese have the 
psychology of praying for all things, and thus form a unique auspicious culture, hoping that things will develop in a beautiful direction, and the auspicious meaning in the logo design will be easily accepted by the audience. China Unicom's logo design (see photo?) is a psychological expectation for people's good fortune. The "China Red" in the logo is the color of the Chinese people's thousands of years of complex, which in turn increases the affinity of the corporate image. Closed the distance from the viewer. The Unicom logo also adopts the "concentric knot" pattern of the ancient Chinese pattern. The four squares in the shape have everything in all directions and everything goes well; the six rounds have the same road and the smoothness of the road; the ten in the sign The holes are full and full of meaning. In short, whether from symmetry or even-numbered, the pattern is filled with the long-awaited auspicious atmosphere of the ancient oriental people.The visual communication design information source is shown below.

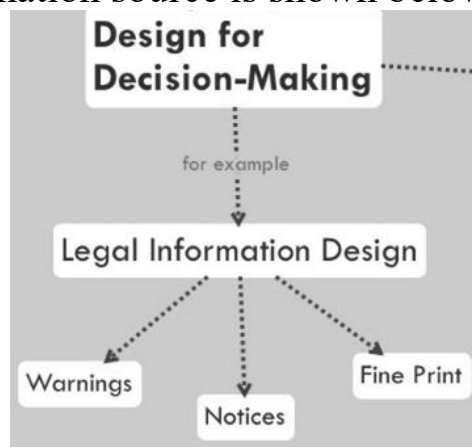

Fig.2 Visual communication design information source

\section{Visual communication professional studio construction and practice teaching reform}

It is the task of cultivating art design education in colleges and universities to train specialized personnel who serve the modernization of the conference. However, the domestic education system mainly focuses on the theoretical form of education, which dilutes the lack of practicality in the cultivation of hands-on ability. In order to solve the defects and deficiencies in this aspect, the design should serve the function. In order to meet the needs of the market, students should highlight the technical and individuality. Turn. The application of talent cultivation to skills is reflected in the perfect combination of technology and function. To this end, we can strengthen the student practice and cultivate the practical application ability by establishing and perfecting the studio system. It is very important. Combine teaching in school and practice in studio theory. In turn, strengthen and improve the reform and construction of practical teaching links. Compared with traditional art education, there are many differences in the teaching methods of visual communication in colleges and universities. The practical characteristics are more prominent, and a large number of practical operation links should be interspersed in the teaching.

\section{Summary}

The construction and research of the subject-based teaching mode of visual communication design is the forerunner of art design teaching. The establishment of teaching mode determines what methods and methods should be adopted, and what kind of teaching plan should be formulated. Therefore, the research of this subject is an inevitable trend of the research and development of art design teaching in colleges and universities.

\section{References}

[1] Jesvin Puay-Hwa Yeo. An overview of research methods in visual communication design education[J]. 
International Journal of Design Creativity and Innovation,2014,2(1).

[2] Wei LI. Innovativeness of Visual Communication Design Teaching in the Digital Times[J]. Studies in Sociology of Science,2016,7(2).

[3] Fatos Adiloglu. Visual communication: design studio education through working the process[J]. Procedia - Social and Behavioral Sciences,2011,28.

[4] Zena O'Connor. Colour, contrast and gestalt theories of perception: The impact in contemporary visual communications design[J]. Color Research \&amp; Application,2015,40(1). 